Please do not remove this page

RMIT

UNIVERSITY

\title{
"Here nobody holds your heart": Metaphoric and embodied emotions of birth and displacement among Karen women in Australia
}

Niner, Sara; Kokanovic, Renata; Cuthbert, Denise; Cho, Violet

https://researchrepository.rmit.edu.au/esploro/outputs/9921859624701341/filesAndLinks?institution=61RMIT_INST\&index=null

Niner, S., Kokanovic, R., Cuthbert, D., \& Cho, V. (2014). "Here nobody holds your heart": Metaphoric and embodied emotions of birth and displacement among Karen women in Australia. Medical Anthropology Quarterly, 28(3), 362-380. https://doi.org/10.1111/maq.12070

Document Version: Accepted Manuscript

Published Version: https://doi.org/10.1111/maq.12070

Repository homepage: https://researchrepository.rmit.edu.au

(C) 2014 by the American Anthropological Association. All rights reserved.

Downloaded On 2023/04/27 00:32:26 +1000 
Thank you for downloading this document from the RMIT Research Repository.

The RMIT Research Repository is an open access database showcasing the research outputs of RMIT University researchers.

RMIT Research Repository: http://researchbank.rmit.edu.aul

\section{Citation:}

Niner, S, Kokanovic, R, Cuthbert, D and Cho, V 2014, "'Here nobody holds your heart": Metaphoric and embodied emotions of birth and displacement among Karen women in Australia', Medical Anthropology Quarterly, vol. 28, no. 3, pp. 362-380.

See this record in the RMIT Research Repository at:

https://researchbank.rmit.edu.au/view/rmit:23565

Version: Accepted Manuscript

\section{Copyright Statement:}

(c) 2014 by the American Anthropological Association. All rights reserved.

Link to Published Version:

http://dx.doi.org/10.1111/maq.12070 


\title{
"Here Nobody Holds Your Heart": Metaphoric and Embodied Emotions of Birth and Displacement among Karen Women in Australia
}

\author{
Sara Niner \\ Anthropology, School of Social Sciences, Monash University, Melbourne, Australia \\ Renata Kokanovic \\ Sociology, School of Social Sciences, Monash University, Melbourne, Australia \\ Denise Cuthbert \\ School of Graduate Research RMIT University, Melbourne, Australia

\section{Violet Cho} \\ Visiting Fellow, Department of Political and Social ChangeANU College of Asia and the \\ Pacific Australian National University, Canberra, Australia
}

Our objective was to explore the ways in which displaced Karen mothers expressed emotions in narrative accounts of motherhood and displacement. We contextualized and analyzed interview data from an ethnographic study of birth and emotions among 15 displaced Karen mothers in Australia. We found that women shared a common symbolic language to describe emotions centered on the heart, which was also associated with heart "problems." This, along with hypertension, collapsing, or a feeling of surrender were associated responses to extremely adverse events experienced as displaced peoples. A metaphoric schema of emotional terms centered on the heart was connected to embodied expressions of emotion related to illness of the heart. This and other embodied responses were reactions to overwhelming difficulties and fear women endured due to their exposure to political conflict and global inequity.

[emotions, embodiment, maternal, displacement, Karen]

[A] child counts on his fingers before he counts "in his head"; he feels love on his skin before he feels it "in his heart." Not only ideas, but emotions too are cultural artefacts.

Introduction

In this article, we explore the findings of an ethnographic study of birth among displaced ethnic minority Karen women from Burma, officially referred to as Myanmar. These women have suffered "the sentence of history - subjugation, domination, diaspora, displacement" (Bhabha 1994:246). Their narratives and associated emotions—represented through language, symbol, or symptom — are considered here not merely as individual psychological reactions but within the wider political and social contexts of their lives. The analysis offered 
in this article considers how the women's narratives and expressions of emotion may have been affected by displacement, disruption, violence, and trauma.

Human emotion and its expression are shaped by culture and shared experience. Yet, any holistic notions of culture have been problematized by the impact of globalization and poststructuralist and postcolonial critiques (Boellstorf and Lindquist 2004:437-439). Extraordinary global political and cultural transformations and population flows have forever altered people's local lived experiences, including their ordinary repertoires of emotional expression. While we explore particular instances of the rich cultural language that describes the "metaphoric and symbolic expression of affect" (Kirmayer 1989:330) as relayed in the accounts of birthing and displacement of Karen women in Australia, we also consider other forms of expression variously referred to as somatization or "idioms of distress" (Nichter 1981) or other embodied representations that may occur when certain forms of emotional expression are either prohibited, inadequate or otherwise impossible.

Emotional distress, such as fear or anxiety may be embodied according to "sociocultural norms for illness behaviour” (Kirmayer 1989:329). Nichter (1981) referred to specific cultural forms as "idioms of distress." Biomedicine, however, has labelled physical symptoms with no identifiable physical cause as somatic, explaining them as a dysfunction caused by the denial of psychosocial stress. These symptoms are then treated as a mental illness rather than a physical one (Keyes 2003:1833-1834). This concept of somatization is criticized as a product of Western medicine's dualistic ontology: the Cartesian split between mind and body (Kirmayer 1988:59, 1989:329).

A more nuanced or holistic understanding holds that such physical symptoms are expression of emotions felt and experienced by the body or embodied, resulting in physical reactions and sometimes illness. Heart distress in particular has been documented in a continuum from mild excitation to heart attack (Good 1997:32). Good's “semantic network analysis” catalogs "symbols and experiences which typically 'run together"” in "patterns of associations" as an "illness complex" or "syndrome." In such alternative explanations, it is understood that the social world is experienced through the body and that emotion mediates this experience (Tapias 2006:403). There are multiple explanations for these processes in particular contexts and for the meanings ascribed to health and illness according to local cultural understandings and proscriptions. Embodied reactions can result from economic hardship, domestic violence, power imbalances, political oppression, national violence, conflict, and injustice and human rights abuses (Jenkins 1996; Kirmayer 1989; Rebhun 1994; Tapias 2006; Volk 2009).

Singer (2008) argues that many forced migrant women in Australia express their trauma symptomatology in terms of traditional models and metaphors. Although Singer accepts that these symptoms may be "somatic representations of distress," she also offers a further theorization of them as expressions of disruptions in community or culture. These disruptions may form part of a "complex narrative of suffering” (Singer 2008:58; see also Kleinman and Kleinman 1991:284). Henry (2006:391) suggests that bodies "become idioms through which expressions of deeply personal and social trauma become manifest.” The body, he writes, "articulates with violence," manages trauma, and transforms and reconfigures it "socially and personally ... and creatively.”

The Study

We carried out this ethnographic study of emotion and birth with 15 displaced Karen women who had resettled in Australia. The study on which this article is based aimed at 
understanding the birth experiences of forced migrant women in Australia and how they conceived of their maternal emotional health (for more information on the research report findings, see Niner et al. 2013).

We purposefully selected women who had recently given birth in Australia from several Karen communities residing in Australia. All women had delivered their youngest child, or in two cases, twins, in Australian hospitals in the previous two years. This enabled the researchers to focus on birth in the women's narratives. The research team had experience with qualitative cross-cultural research with individual expertise in areas of mental health and illness, narrative research, gender, ethnography, and policy and political aspects of families in Australia. A key approach of building engagement with the community was implemented through the employment of a bilingual research assistant (RA), Violet Cho, who shared language and experiences of displacement and forced migration with participants. Cho acted as a co-researcher and cultural informant, including providing information and insights into the socioeconomic, language, religious, and historical differences within the community.

All participants chose to be interviewed in their mother tongue, Karen (see below for discussion on language) in their own homes. The use of the mother tongue, along with the security felt by being interviewed in home environments, offered the best setting for participants to articulate fully their emotional experiences. Interviewing in the mother tongue assisted in capturing finely grained meanings embedded in the women's narratives and the social and cultural contexts of women's emotional experiences, uninhibited by language barrier or use of interpreters (Oo and Kusakabe 2010). Interviews were conducted as tapoetethako (informal chatting), in the mode of close friendship or kinship norms for the sharing of personal experiences (Cho 2011). Interviews were audio-recorded, transcribed verbatim by Cho into Karen script, and then translated into English. To illustrate our findings, extensive quotations from these interviews follow here.

The translation of language used to describe emotional experiences was a topic of ongoing discussion among the research team, resulting in the development of a glossary of Karen emotional terms that emphasized that many of these words related to the heart. This work led to the recognition of how emotions were narrated by women as a central theme in the emerging data. Our research provides the first analysis of how Karen women narrate or represent their emotions. We describe this in terms of a metaphoric schema of the heart and its functions (in a similar method to Good 1997). Our analysis of Karen women's narratives is mediated throughout by an acknowledgment that their experiences and corresponding emotions have been shaped through often traumatic encounters in a postcolonial world, and this understanding frames the presentation of women's accounts.

\section{Findings}

Participants

All participants had come to Australia since 2006 through humanitarian migration programs. The troubled history of those displaced from Burma has been recognized by the Australian government (DIMA 2006), and this has been reflected in an increase in the immigration program for Burmese-born displaced peoples (DIC 2010). Although there have been some promising recent political developments of democratic reform, the government of Myanmar has documented patterns of human rights abuses of civilians, including military attacks in ethnic minority areas, resulting in civilian deaths, forced relocations, and sexual violence (Physicians for Human Rights 2012). Security forces are responsible for extrajudicial killings, rape, and torture (U.S. State Department 2011). It is estimated that since 1996, over 
3,500 villages have been destroyed, forcibly relocated, or abandoned in eastern Burma, particularly in the ethnic Karen, Karenni, and Shan States, creating almost 500,000 internally displaced persons and two million who have fled the country. Most Burmese-born humanitarian entrants to Australia have been living in refugee camps for more than a decade before they arrive (Queensland Health 2011).

Socioculturally, Karen is a polysemic term. Depending on the context, it holds different meanings. Further, it serves as an umbrella term for an "(ethno)nation-making project” that unifies approximately 20 ethnolinguistic groups (Thawnghmung 2008:3). After Burma’s independence in 1948, the core Karen ethno-nationalist organization, the Karen National Union, rebelled and began an armed struggle that continues today. This long struggle has created a broad "narrative of suffering," in which suffering and sacrifice have become the core emotional experiences of being Karen. Due to nationalist imperatives to create unity and obscure differences among Karen groups (Cheesman 2010; South 2007), issues of language and religion are sensitive. The two dominant Karen languages are S'gaw and Pwo. S'gaw has become the lingua franca of the Karen resistance movement and is the language that all but one of the interviews in this research project was conducted in. As only one interview was conducted in Pwo, linguistic discussion here is limited to S'gaw Karen and Burmese (B.) loanwords.

Aged 20-47, the women recounted narratives that spanned several generations and phases of the political history of Burma. Older women had fled political persecution, violence, and military attacks on their natal villages during the 1990s as young women, often with their own small children. Younger women had arrived in refugee camps as children with their families, and the youngest women had been born and lived most of their lives in the different camps along the Thai-Burma border. The largest family in the study included eight children; the three youngest mothers had one child each. Children ranged in age from 21 years to one month: the oldest born in villages in Burma or while fleeing persecution and younger children who had been born in refugee camps or small rural hospitals in Thailand. Fear and trauma were associated with memories of bombardment, violence, loss, and separation from close family and the hardships of surviving in conflict zones and refugee camps.

This demographically diverse range of women shared similarities and differences in experiences and expression of emotion. Younger women had experienced less time in armed conflict zones, where adversity was extreme, and a larger proportion of their lives in refugee camps, where somemeasure of protectionwas afforded. They seldom mentioned personally experiencing political violence and military attacks, but several spoke of attacks on refugee camps or ongoing fear of such attacks. However, symbolic violence was pervasive in their lives and presented in their accounts through shared family histories and through long-term residence in refugee camps in close proximity to conflict zones. Although it varied according to age and experience, all narratives included accounts of lifetimes of adversity and alterity: first as persecuted ethnic minority peoples in their homeland, then during long periods as displaced persons in refugee camps, and finally as forced migrants in a foreign environment. Although there are similarities in how women narrate their emotional experiences, we are mindful of their individual agency in this regard and of the diversity of their personal responses.

In their narratives, women recounted the basic facts of lives in poor Karen villages or refugee camps (or both) and conflict zones in Burma and in refugee camps. Women often described terrifying situations in conflict zones as simply "hard" or "difficult," with little elaboration. 
As Janis Jenkins (1996) found in her work with Salvadorian women, traumatic narratives tended to be expressed either in heightened language or in very mundane ways, much like the Karen women here represent extremely difficult experiences. Jenkins concluded that these were simply different modes of presenting the same profound emotional response (Jenkins 1996: 286).

The Karen women in this study focused on physical hardships and associated physical illness that may be interpreted in some circumstances as embodied distress. Women commented that they did not focus on their own feelings or emotions, as their lives were dominated by more pressing concerns of physical survival (see also Niner et al. 2013). Most women felt there was little point in complaining or dwelling on their distress because everyone around them was experiencing the same hardships. Generally, women did not talk about their emotions, which may be explained by the survivalist ethos outlined above, feelings of alterity or inferiority, and the notion of the kaw tha (the disturbed heart): a state marked by difficulty in expressing desires or negative feelings. In a process similar to that of Karen women described here, Good explains the heart distress of Iranian women in his case studies as providing a cognitive framework for illness tied to particular social stresses "experienced, communicated and dealt with as heart ailments” (Good 1997:32).

The gendering of emotions was apparent in Karen women's narratives. Nin Htoo, a 40-yearold mother of three, expresses this explicitly. Reflecting on her role as a community worker, Nin Htoo provided articulate insights into Karen women's reluctance in discussing emotional distress or personal reactions to hardship as a gendered position that was culturally expected:

We Karen women think that our personal suffering is not important. The most important in our life is our children's life and the family as a whole. We think that depression cannot kill us and we have to be strong in the face of anything. So women ignore these sorts of feelings and compared to what they have gone through, these feelings are not significant.

Similarly, Jenkins noted Salvadorian women's need to "control themselves-to harness their anger and fear," remarking that this imperative to suppress negative emotion was common for women all over the world (Jenkins 1996:287). Jenkins has also noted the gendering of tenacity and self-sacrifice in cultures surviving conflict (Jenkins 1991, 1998:128; Jenkins and Valiente 1994). The cultural imperative to put negative emotions aside has led to stoicism apparent in many Karen women's narratives of motherhood and survival gathered in this study. A "politics of emotional expression" dictates who may express emotion according to power relations of gender, ethnicity, class, and age (Rebhun 1994; Tapias 2006:404). Women's negative emotions, unable to be expressed, may therefore become transformed into other forms such as idioms of distress or somatized symptoms or embodied emotion (Rebhun 1994).

Although there are similarities in how women narrate their emotional experiences we are mindful of their individual agency in this regard and the diversity of their personal responses. Variation also exists in how women speak of their heart distress, from the more educated or experienced women who add Burmese (or other language) terms to their repertoire to those who still use Karen terms exclusively. Perhaps because of the "politics of emotional expression” outlined above (Rebhun 1994; Tapias 2006:404), some women felt more able to articulate and express emotions according to age, education, or class. Further, similar experiences elicited different responses such as those traced below among women who gave 
birth under the most extreme conditions in conflict zones or in the more benign yet (for women in our study) perplexing environment of Australian hospitals.

“I Wanted My Heart to Stay Very Tight”: Karen Emotional Expression.

Emotions are commonly represented symbolically through language. In the Karen women's narratives, the embodiment of emotion in certain parts of the body, commonly the heart, is expressed through language and metaphor. Women drew on a linguistic and metaphoric repertoire to represent emotions confirming the recognition of "the enormous diversity in the way individuals appropriate symbolic forms related to emotions" (Good 2004:532). Women mostly described their emotions as physical sensations related to the heart. How these words were used by women in relation to specific events in their lives is represented schematically in a diagram that appears online with this article.

Karen languages have rich metaphors for the heart as the repository of emotion and distress. This is a feature of a wider culture apparent through the use of common metaphors based on the root word for heart or consciousness (tha). This semantic connection between heart and mind create a schema in which emotions are always felt in the heart, rather than the brain or mind. As one of the participants (Eli Moe) notes below, distress can also come from "thinking too much" or dwelling on difficulties or disruptions and this can cause heart distress. There is obviously a significant relationship between the heart and mind, but we focus here on our central finding that the symbolic language of the heart was the primary and most common way women communicated their emotions during the interviews.

During the interviews, participants used a range of words and phrases in Karen referring to the emotions. Burmese terms were employed in the same way, using the root word sate although this was less common. The word for happy in Karen is thamu (good heart) and unhappy thatamu (bad heart). To have high spirits or a strong heart is thashu. Further compound words were used such as yathasho, heart disturbed (feel confused); thabapor, poor heart (feel unhappy; sad); thahagaw, heart damaged (a feeling of hopelessness); thabardoe, heart hurt (feeling hurt); and thakoe, heavy hearted (worried, anxious).

Women used these different words to describe a range of emotions. Pee Lee, a 30-year-old mother of two girls and one 10-month-old baby boy, used the word thatamu (unhappy) to describe her feelings on hearing of the death of a woman in labor who stepped on a landmine. Yee, a 38-year-old mother of five, use thatamu to describe the emotion of a mother losing a baby compared to the lesser worry or anxiety, thabayo and thakoe, which a mother would feel for her children when they were sick, particularly when there was no medical assistance available. Mah Sha, a 35-year-old mother of six, who had been separated from her parents during the conflict in Burma and subsequently undertook a traumatic childhood journey to a military camp to be reunited with them, used a Burmese and Karen combination: "When we lived in the camp I felt satemachantha (heart is not rich).”

Women also explained how they tried to control negative heart sensations so they would not be overcome by them. Ela, a 33-year-old mother of five, explained how she and others survived years of hardship in the refugee camps by "controlling your heart." She added: "It is better if you can control yourself. Personally, I am good at it.” A sense of strength and will power was consistent with the ability to control the heart or consciousness, tha, and losing control of it was feared. Nin Htoo described how she "could not control my heart" due to the distress she suffered after the birth of both of her children in the uncertain and deprived conditions of a refugee camp and how this led to severe distress: 
I wanted my heart to stay very tight. I didn’t know to manage my heart so all the tears came out. After I cried I felt better and I thought I couldn't die although I wanted to die. I wanted to forget about the world and I didn't want to hear anything. I just slowly controlled my heart. . . . I am not sure how to name this feeling in Karen but the Burmese word satedatkya (falling/failing power of the heart/mind) is how I would put it. I felt too over-anxious about things and my heart was satepyae (B. demoralized; downhearted) and sategon (B. fed up; lost interest). I really wanted to forget about the world. Even though I felt satepyae, I also thought about my child. It was so painful and I could not control my heart.

Describing emotions, as Nin Htoo does here, through symbolic metaphor related to the heart as a site of embodiment, is culturally shared among the women as we have shown above. When she describes wanting her heart to stay tight, she means that she wanted control her emotions. Crying or shouting and other negative emotional expressions are seen as coming from a "loose" heart, and the imperative is to control or not show them. However, the heart is not the only physical site for emotions.

The Unstable Heart: Embodiment of Emotion.

The embodiment of emotion expressed as a physical sensation might also usefully be extended to other physical sensations the women describe, although this is less obvious than the explicit use of words and metaphors to represent emotional experiences. There were many examples in the interviews of physical complaints that were not clearly defined that may well be described as somatic or as embodied emotion or distress. Health problems with no clear biomedical cause or diagnosis were often satisfactorily treated at home with alternative medicines, nutritious foods, heat, care, and massage. Many lesser complaints were described, but we have focused here on two particular physical reactions: hypertension and collapse.

In almost every interview, participants referred to heart problems or disease (hna lounjoga) or hypertension or high blood pressure. Although this may be explained by the poor diet and general health of forced migrants, it was often associated with distress or high levels of embodied stress. This association is similar to that described by Henry (2006:387), who "was amazed at how many people seemed to be suffering from 'heart problems'” among the Liberian survivors of war he interviewed. Henry suggested that heart complaints "had come to be associated with the war, or with the violence and fear that people experienced" (2006:387). He notes that these conditions were previously referred to as "spoiled heart," "heart cramps," or "heart pain," but, since the war, had come to be grouped together and described as hypertension or haypatensi in the local language but had a different meaning than the Western biomedical one (Henry 2006:388).

Similarly, hypertension, high blood pressure, and heart disease were commonly associated by Karen women with conflict, suffering, negligence, or nonobservance of customary practices (often because of displacement). Although some women mentioned being diagnosed with high blood pressure or hypertension, particularly when pregnant, it was often not clear how they had been diagnosed. Due to the emergency or ad hoc medical treatment women had received and significant language and semantic barriers, it is difficult to make clear conclusions about women's symptoms in this regard.

Nin Htoo spoke about this at length in relation to the long-term suffering of older Karen, like her grandmother, who died in a refugee camp while waiting for resettlement: 
Their heart is not stable anymore: I think some even have heart disease. They have suffered extensive levels of anxiety (like my grandmother who could not sleep for a long time because so many of her children had died). . . . My view is that their heart is not stable anymore but it is not a disease, like heart failure . . . but because of too much pressure and suffering for such a long time.

This description by Nin Htoo resembles the complaint of "nerves" common in Latin American cultures, where it is understood that the nerves may become "worn out by too much use in the form of worry and tension or the accumulation of shocks" (Rebhun 1994:369).

With respect to the focus on emotional experiences of birth in our study, many participants shared their understanding of a link between emotional distress and high blood pressure or heart problems that may manifest itself during pregnancy and birth. Like all aspects of the women's life, pregnancy, birth, and motherhood were affected by the conflict and displacement they had endured. Mah Sha said she felt like she got heart disease because she was forced to give birth out in the open after a military attack had destroyed the refugee camp where she lived. She reflected that afterward, "my mind was not stable, and I felt like I got heart disease."

EliMoe, a 20-year-old mother of two who grew up in refugee camps and married at 17, described the postnatal period as one where the mother must be closely cared for by her family, particularly her husband, and that, "if their husband does not look after them and help them they will think a lot and will have hypertension, which can kill them." Not receiving the correct care, resulting in the distress of "thinking a lot," usually a euphemism for worry, is then associated with fatal hypertension.

Like Eli Moe, other women believed that hypertension was a danger associated with lack of attention or disruptions to postnatal cultural proscriptions for health. The avoidance of cold temperature, such as cold water and rain after, birth was mentioned by most women. Mah Shah noted that: "You cannot wash your head and hair because people worry that you will get high blood pressure.” Lah, a 33-year-old mother of five, recommended that women who are exposed to a cold environment after birth would suffer three main ill effects: "Probably they might have high blood pressure and they can start to shiver; and also they might suffer from menstrual disorders [later in life]. Also they might have a stroke.” Lah appeared to treat her own complaints of hypertension, "cold heart," and temporary blindness successfully at home with traditional methods of heat and massage. The strong belief that disregarding postnatal cultural proscriptions led to ill health is explored further below in Lah K'por's narrative of collapse.

Less frequently, experiences of collapse or loss of consciousness were mentioned in women's accounts. These were associated by the women with high blood pressure. Collapse occurred in extremely adverse situations where a nexus between the ongoing events of adversity and physical and emotional responses was highly likely. However, it is difficult to draw conclusions from the evidence presented because participants' descriptions of their physical sensations or symptoms are mediated by women's own cultural and personal understanding of their health. Events described by the women of extreme mental and physical hardship may account for a physical collapse. Perhaps, too, in these extraordinary circumstances the available repertoire of emotional responses was inadequate to encompass the experience. 
We are not in a position to determine whether the hypertension and loss of consciousness described by some women in this study are somatic expressions of emotional distress, but we cannot discount or ignore that there would certainly be emotional reactions to the events and circumstances as described by the women. Likewise, as there are challenges in attempting to disentangle cause and effect in the experiences described by the women, the experiences and the women's understandings of them are more appropriately viewed through a holistic lens This follows Singer's view, who suggests that pain is better considered holistically as "a bodily sensation and as an emotional state of being, both with socially mediated meanings" (Singer 2008:48).

We may consider pain this way in the story of Lah K'por, a 48-year-old mother of six children whose family were rural subsistence farmers in Burma with no access to education. Military attack and destruction of her village precipitated a flight from her home on foot with her family, including her first child, while heavily pregnant with her second. As they made their way through the mountains, she gave birth in the jungle. Continuing military attacks meant that their journey had to resume as soon as possible after delivery:

When I arrived on top of the mountain I could not walk anymore. I suffered from korlorblay (paraplegia). I think I ran out of strength because I climbed up the mountain in a delicate state of health so soon after I gave birth. I think all my brown blood had not gone yet. We decided to stay in an abandoned house but we could hear the sound of guns all night. If we died then we died but we couldn't do anything else.

The fear of the family must have been acute, but Lah K'por notes the circumstances in the mundane fashion described by Jenkins, which might also be the result of "a combination of political constraints on expression and the psychological suppression of response” (Jenkins 1996:286). Lah K’por's physical complaint of korlorblay, translated as paraplegia, appears to be result of a combination of physical exhaustion, her terrifying situation and embodied fear. Lah K'por, however, explicitly points to her inability to fulfill customary postnatal practices such as rest, care by family, and heat and nutritional treatments. Lah K'por believed these proscriptions would have released her "brown blood" and restored her humoral "bodily balance” and health after birth (see Manderson 1981:509-510; Ram 1998:293), but as these were not observed, Lah K'por's health was damaged. Rather than seeing Lah K'por's paraplegia simply as a physical response or a somatic symptom, it might be understood as a reaction to severe disruption in community and culture and understood as an expression of a “complex narrative of suffering” (Kleinman and Kleinman 1991:284).

Mah Shah, mentioned previously, had her first child in a refugee camp after she was married at 16. Her third child was born two days after the camp was destroyed in a military attack. After delivering her child out in the open at night with no midwife, Mah Sha's descriptions of her feelings afterward are understandably extreme:

I was so frustrated. Nothing serious happen to me [physically] but I became pwe-pwe (psychologically very light; mad). I felt that it didn't mean anything to live or die. I just gave myself to God. I lived but I was unhappy that we had to be afraid day and night. I felt like I was crazy. . . . I nearly died. I felt like I could either live or die. I felt satedatkya (B. the failing or falling power of the heart). 
The birth was followed by frightening hallucinations that continued for "about six or seven months," which have continued to occur after later births. Mah Shah's response of surrender or giving herself to God, related to being pwe-pwe or "crazy," was an emotional response to the fear she felt, her vulnerability and her unbearable situation. Her word for this feeling was, satedatkya, translated from Burmese as the failing or falling power of the heart. Using Jenkins’s (1996) framework, Mah Shah’s extreme response is compared to Say Say’s mundane one.

Say Say, a 43-year-old mother of eight (including 16-month-old twins born in Australia), was pragmatic about the events of her life as a refugee and appeared resigned to the difficulties she has faced. As a young woman she trained and worked as a nurse in the Karenni resistance movement. She displayed bravery remarking, “I wasn't afraid of anything, not of ghost or spirits. The only thing that I was afraid of was the Burmese army. They can kill you.” After meeting her husband, a soldier in the Karenni National Progressive Party, she married and had her first child when she was 24 in the conflict zone in Burma, then she had five more children.

Her stoicism is apparent in her descriptions of the births of her third and fourth babies in similarly terrifying conditions to those of Lah K'por andMah Shah: fleeing military attacks and giving birth in the open with no midwife or medical assistance. Like Mah Sha, Say Say describes her reaction similarly as a spiritual surrender-laying her life in "God's hands":

When I gave birth I didn’t have anything. I didn't have a candle so I used dry bamboo to make fire for light. I couldn't see things clearly. . . . It was like that until the sun rose again. . . Well, it was really hard but we were blessed by God who looked after us and let us live, otherwise we would have died. . . . I could not do anything so I lay my life into God's hands: whether I would live or die. I had to keep going like that.

The disembodied space of God's hands that Say Say describes allowed her to keep going and survive. While the women's narratives recounted above offer three different embodied reactions to similarly extreme situations, each woman attempts to describe her emotions using a common repertoire of cultural terms and concepts.

"Here Nobody Holds Your Heart”: Life after Resettlement.

Similar to many forced migrants, the journey to Australia formost in this study had been bewildering and unsettling. Lah, who received no formal education as a child, instead starting farming work from an early age, said they were like "blind chickens" during the plane trip to Australia. The loss of a familiar environment is keenly felt by forced migrants (Killingsworth et al. 2010; Niner et al. 2013). A central emotional challenge for women in the study after resettlement appeared to be the loss of family, particularly of mothers and grandmothers, which was also closely related to a loss of cultural knowledge.

Pee Lee, mentioned previously, grew up in a Karen village in Burma. After being persecuted by the Burmese military, both her parents fled and she was separated from her mother. The succession of events is remembered with particular trauma. Forced to embark on a traumatic journey by foot through mined zones, she arrived at a refugee camp: 
I felt like my tha was not attached to my body anymore. Although I was still a kid I was so scared of the Burmese Army. . . . We lived in fear like that throughout 1995. ... [ [When we reached] . . . the refugee camp I felt like our family burden was a fire that had been put out by water: completely gone.

She attributed the emotion of her heart being outside her body, or being scared, to being abandoned by her mother during a period of intense danger. Memories of this trauma resulted in her refusal as an adult to migrate and leave her mother again. However, at her husband's insistence, she was persuaded to resettle in Australia. On arrival in the depths of a harsh winter, Pee Lee described being cold beyond her imagining and of how unfamiliar smells evoked feelings of revulsion.

I felt so cold and I felt sick but I forced myself to get things done. ... Things were different when I first arrived and I could not tolerate any smell. I could not bear the smell of people's bodies. I don't understand that now. It was so strange. The second thing was that living was not the same as before anymore. Food here is not similar to food in the camp. I could not tolerate the smell of it as well. I don't know what was wrong with me. I went around in the cold so I got a fever and then I did not feel like eating and that made me feel like I did not have strength. I got dizzy and sick. I was so sick and ended up in the emergency room. ... . I thought I'd come Australia to die.

Pee Lee's stoic nature had forced her to continue with the round of tasks required on arrival, and after days of feeling dislocated and highly stressed in an environment incomprehensible to her, she developed a lung infection and eventually collapsed in the emergency department of a hospital. Pee Lee attributed her collapse to her feelings of unease, to not eating, and then the lung infection. However, her narrative also focuses on the emotional element: "When I woke up I felt so miserable and upset. I started crying. I missed my mother so much. I told myself that my husband was trying to kill me by bringing me to this strange country. I accused him of separating me and my parents.” Pee Lee had a profound emotional reaction to the separation and loss of her mother and extended family and an extreme sense of displacement in her new environment. She continued that they now have everything material they need but her heart still misses her parents. These continuing "heart" problems in resettlement were also described by other women in the study.

Interviews with women were conducted during a particularly cold winter in the southern states of Australia, and the houses researchers visited were mostly unheated and sparsely furnished. Relative to the socioeconomic standards of Australia, Karen families could be described as underprivileged. Most of the homes were far from urban centers, with little access to transport, social services, and shopping. Several women mentioned being housebound due to their fears of becoming lost and unable to communicate. Their lives differed markedly from the communal village and camp life in more tropical climes that women were familiar with. Even though life in the refugee camps had been tough and a severe disruption from natal villages, environments were similar and social, cultural, and family structures had survived. In Australia, most women lived in nuclear families and missed the communal solidarity of villages and camps. Several women mentioned having few people they could rely on for help and that people in Australia tended to work hard and only look after themselves. 
Most women expressed a greater sense of physical security and remarked that their socioeconomic situation had improved since their arrival in Australia. This sense was focused on basic necessities such as having enough food to eat, running water, and reliable electricity. However, positive aspects of living in Australia as distinct from life in a conflict zone or a displaced person camp were somewhat compromised by the challenges they faced in resettlement. Although they felt better off in terms of having their basic needs met, life was still considered hard.

Wah, a 31-year-old mother of a baby girl who fled from the Burmese army as a young child with her family, explained that even though things are better in Australia, she still finds: "some difficulties related to my heart here. Here you always have to push yourself and if you don’t then you will be left behind. You have to try even if you are not confident.”

Finding themselves in an unfamiliar environment created new concerns and emotions to contend with. Older women bought up in traditional and rural environments were less able to manage this "pervasive social change" (Tummala-Narra 2004:168), and the disjuncture appeared insurmountable. For Say Say, who emphasized that life in Australia is far better than Burma and the refugee camp, there was some disappointment about her loss of authority and agency as a nurse because she believed that she could never catch up to the level of expertise required of nurses in Australia. Say Say and others also mentioned their loss of authority with their children since arriving in Australia.

For women who were illiterate, there was a lack of hope of ever learning English or feeling a part of awider Australian community. Many women, like Baw, described the emotional impact of their difficulty or inability to communicate in English, which was compounded by the lack of interpreting services available to them. Among the older women, difficulties with English language and lack of social engagement in wider society led to feelings of isolation and marginality. Many spoke about not going out because they felt they couldn't find their way around or ask for help if they got lost. Baw, a 29-year-old mother of five young boys, explained that she hid if she saw strangers coming to her house because she was scared:

I can't speak English, so it's not easy in this country. It's very hard. . . . I am scared of kawlawah [white] people so if I see them coming to the house, I try to hide because I worry that I cannot respond to them when they ask questions. Sometimes when people come to drop letters off I tell my son to come with me and hide. I worry that they will come to my house and I won't understand what they say.

Prior education was key to more successful resettlement, and several of the younger women who had finished high school in a refugee camp had continued to study at tertiary institutions in Australia and go on to work. Through work, relationships were developed with a broader Australian community. Wah talked about how much support she received from work colleagues when she was pregnant:

I had friends at work who were also pregnant. Four of us were pregnant at the same time and we talked about how to look after yourself and what sort of medicine to take when pregnant. I gained knowledge from talking to them and I feel like I received support from my friends at work too. 
While Wah's command of English language was good, most women experienced difficulties associated with communication in English. This was most pronounced in narratives about birthing in Australian hospitals. Combined with what they perceived as lack of personal care in the hospital, this created negative experiences (Niner et al. 2013). Feeling scared was common, even though many praised the attentions of the nurses (one saying the nurses looked “after her like their sister”). Quoting Lah K’por again:

The nurses [in Australia] do not like people to touch us [in labor] so I had to bear the pain alone until the baby was born. . . . In Burma the midwives touched us and gave a small push here and there. They held the baby from here [holding her lower chest]. I think it is holding your heart because when the baby is out I felt like my "heart became loose.” Here nobody holds your heart.

The emotional distress that the perceived absence of support caused was common; there was a sense that without this support, the pain of childbirth was harder to bear.

"How We Survived": Self-Reliance.

Self-reliance was described by many participants as key to survival and provided insight into the different ways they had "kept going." Some, like Ela, as we have seen, advocated a strategy that involved "controlling your heart.” Hsa, a 28-year-old mother with one baby girl born in Australia, had been born and lived in a refugee camp until she was 23. She had developed multiple strategies to deal with adversity, like walking and talking things over with her family and colleagues. Although Nin, a 26-year-old mother of four, was receiving psychological counseling, she also had developed her own personal strategies: "to comfort myself sometimes I turn the music on, I will listen and sing along. . . . I watch videos. . . . I find comfort in playing games because I can bury my heart there.” Pee Lee, who misses her mother back in the refugee camp intensely, had made a connection with an elderly Italian neighbor. This particularly maternal figure had made her feel less isolated even though they did not share a common language.

All of the women interviewed had found great solace in spirituality, Christian, Buddhist, and Animist. Most women believed their lives were in God's hands and prayed during times of adversity. Nin Htoo was a great advocate for Buddhist meditation. Similar to a U.K. study on marginalized ethnic minority mothers, it appears that "spirituality was a powerful weapon for dealing with adversity” (Edge and Rogers 2005:20).

As well as the strategies of self-reliance and agency described above, women were also enthusiastic to talk and share their experiences as part of our study and some saw it as an opportunity to address a wider audience and make requests or suggestions. Others had had difficult experiences with the Australian health system (Niner et al. 2013) and used the interview to bring these to wider attention. Finally, Say Say, the most politically active of the women, wanted to participate in the study because, she said, 'I want people in this country to have more information about the situation in our country and for them to know how we suffered and understand how we survived.” Say Say did not think Australians appreciated the adversities Karen people had endured and she wanted them to know how and what she had survived.

\section{Discussion}

In this research, we address the absence of "voices of marginalized and vulnerable groups" in medical anthropology debates (Sargent 2012:857). Such cross-cultural research however is 
difficult, not just logistically, but conceptually as Bhabha suggests: "The transnational dimension of cultural transformation - migration, diaspora, displacement, relocation - makes the process of cultural translation a complex form of signification" (Bhabha 1994:247). Yet we believe this article has provided insights into the experiences and emotional responses of one such group of people.

Many of the women in our study have described extreme and long-term experiences of hardship with little time to consider much else but survival. Expressing emotions focusing on their own experiences was constrained by a combination of gendering, suppression of emotions, and alterity. But the narratives of survival and distress that did emerge provided rich descriptions of the emotional labor women undertook to control their hearts, or simply survive difficult circumstances and then later try to recapture their hearts and spirits.

The Karen women shared a cultural repertoire of emotional expression, much like the "cultural artefacts" Geertz (1973) refers to in the epigraph. In the extraordinary narratives of violence, displacement, and hardship women recounted, we found a catalog, "semantic network," or cultural schema of emotions, embodied in the heart and described through shared metaphoric language. Physical sensations associated with feelings of anxiety for some became symptoms of illnesses, in particular heart disease. This schema lent itself, similar to Henry's (2006) Liberian example, to being stretched to accommodate the strong responses of fear, terror, sadness, and resignation that women had felt in relation to the extraordinary experiences of war sometimes combined with giving birth. A bricolage of old and new meanings included reconfigured understandings of heart problems, high blood pressure, and hypertension.

Despite variation in how women described these emotional experiences, common references to the heart was suggestive of a deeply cultural meaningful and robust medium of communicating personal and social pain and distress. Diversity within this small sample existed according to individual reactions or agency, education, experience and the "politics of emotional expression.”

This schema also included other physical conditions or complaints related to descriptions of events that were unbearable to the woman. In the instances of Lah K'por's collapse on the mountain, Mah Shah's descent into pwe pwe, Say Say's surrender into God's hands, and Pee Lee's shock and collapse on her arrival to Australia, all women had endured the breakdown of familiar structures of society and their culturally embedded modes of emotional expression. Fear of violence or the unknown became overwhelming at a time of extreme physical and personal vulnerability. That the women responded in the way they did, unable to verbally describe experiences and feelings, opens up the possibility that such distress might have been transformed into somatic representations. However, these losses of control may represent expressions of the disruptions to women's lives, communities and culture and constitute a complex narrative of suffering (Kleinman and Kleinman 1991).

Increasing international migration undermines established cultural forms (Boellstorf and Lindquist 2004:439). We emphasize the distressing effects of the postcolonial experiences of displacement, homelessness, arduous transnational travel, and forced migration into foreign cultures for the women in our study. The explication of key emotional constructs of forced migrants, such as we attempt here, may provide insight not just into understandings of emotions but also into the localized movements and experiences of forced migrants, as a 
reflection or critique of the global political order that compels these movements of people (Good 2004).

Many of the women's narratives also demonstrate how most were not destroyed by adverse events: How they were stoic as their war-torn culture expected them to be; how they normalized distress and reduced the "potency of adversity"; and how they survived and have continued to care for their families. The strength of the Karen women we interviewed is illustrated through the many ways in which they have dealt with difficulties and emotional challenges, predominantly through self-reliance and mutual networks of support. However, as Kirmayer (1989:336) suggests, the suppression of distress can be a means of successful coping or a source of suffering in its own right. We can see both in the stories of the women here. The imperative for Karen women to present themselves as calm, strong, and stoic and to ensure family welfare under adverse conditions has been noted among other women in the world, one example being Caribbean mothers in the United Kingdom (Edge and Roger 2005). Also emphasized here are the limits to women's physical and emotional labor and the danger for women of continuing to manage numerous challenges, which result in strain and ill-health (Edge and Rogers 2005:18).

Women's descriptions of physical reactions or complaints may also be understood as embodied reactions to dislocation, adversity, and structural inequality. Anthropologists are increasingly working with communities affected by such circumstances as the global financial crisis, state violence, exploitation, migration, "hegemonic gender politics of postcolonial states," and the emotional effects of these phenomena (Good 2004:529). The analysis we present in this article contributes to this significant new direction in research, and our focus on the relatively under-researched Karen contributes to understandings of their experiences and health.

\section{Acknowledgments.}

The authors would like to acknowledge participants for their time and for sharing their experiences with us. This research benefited greatly from the knowledge, determination, and skills of the research assistant Violet Cho. We also acknowledge the support of beyondblue: the national depression and anxiety initiative, for the original research on which this article draws, and the support of Foundation House (The Victorian Foundation to Survivors of Torture) for the literature review that has informed development of this research. Thanks are also owed to the School of Political and Social Inquiry in the Faculty of Arts, Monash University.

Note

In this article, Burmese words are romanized using the Library of Congress system. As there is no international standard of S'gaw Karen romanization, S'gaw words are transliterated in a way that as closely as possible reflects their sound.

\section{References Cited}

Bhabha, H. K. 1994 The Location of Culture. London: Routledge.

Boellstorf, T., and J. Lindquist 2004 Bodies of Emotion: Rethinking Culture and Emotion through Southeast Asia. Ethnos: Journal of Anthropology 69:437-444.

Cheesman, N. 2010 Seeing “Karen” in the Union of Myanmar. Asian Ethnicity 3:199-220. Cho, V. 2011 Searching for Home: Explorations in New Media and the Burmese Diaspora in New Zealand. Pacific Journalism Review 17:194-209. 
Department of Immigration and Citizenship (DIC), Australian Government 2010 Settlement Reporting Database. http://www.immi.gov.au/settlement (accessed December 15, 2010).

Department of Immigration and Multicultural Affairs (DIMA) Australian Government 2006 Burmese Community Profile. http://www.immi.gov.au/living-in-australia/deliveringassistance/government-programs/settlement-planning/_pdf/communityprofileburma.pdf (accessed December 15, 2010).

Edge, D., and A. Rogers 2005 “Dealing with It”: Black Caribbean Women’s Response to Adversity and Psychological Distress Associated with Pregnancy, Childbirth, and Early Motherhood. Social Science and Medicine 61:15-25.

Geertz, C. 1973 The Interpretation of Cultures: Selected Essay. London: Hutchinson.

Good, B. J. 1997 The Heart of What's the Matter: The Semantics of Illness in Iran. Culture, Medicine, and Psychiatry 1:25-58.

2004 Rethinking "Emotions" in Southeast Asia. Ethnos: Journal of Anthropology 69:529-533.

Henry, D. 2006 Violence and the Body: Somatic Expressions of Trauma and Vulnerability during War. Medical Anthropology Quarterly 20:379-398.

Jenkins, J. 1991 The State Construction of Affect: Political Ethos and Mental Health among Salvadoran Refugees. Culture, Medicine, and Psychiatry 15:139-165.

1996 The Impress of Extremity: Women's Experience of Trauma and Political Violence. In Gender and Health: An International Perspective. C. Sargent and C. Brettell, eds. Pp. 278-291. Englewood Cliffs, NJ: Prentice Hall.

1998 The Medical Anthropology of Political Violence: A Cultural and Feminist Agenda, Medical Anthropology Quarterly 12:122-131.

Jenkins, J., and M. Valiente 1994 Bodily Transactions of the Passions: El Calor (The Heat) among Salvadoran Women. In Embodiment and Experience: The Existential Ground of Culture and Self. T. Csordas, ed. Pp. 163-182. Cambridge: Cambridge University Press.

Keyes, C. L. M., and C. D. Ryff 2003 Somatization and Mental Health: A Comparative Study of the Idiom of Distress Hypothesis. Social Science \& Medicine 57:1833-1845.

Killingsworth, B., H. Tran, and C. Dowrick 2010 A Care-full Diagnosis: Three VietnameseAustralian Women and Their Experience of Becoming “Mentally Ill.” Medical Anthropology Quarterly 4:108-123.

Kirmayer, L. J. 1988 Mind and Body as Metaphors: Hidden Values in Biomedicine. In Biomedicine Examined. M. Lock and D. R. Gordon, eds. Pp. 57-93. Dordrecht, Netherlands: Kluwer Academic Publishers.

1989 Cultural Variations in the Response to Psychiatric Disorders and Emotional Distress, Social Science and Medicine 29:327-339.

Kleinman, A., and J. Kleinman 1991 Suffering and Its Professional Transformation: Toward an Ethnography of Interpersonal Experience. Culture, Medicine and Psychiatry 15:275-302.

Manderson, L. 1981 Roasting, Smoking and Dieting in Response to Birth: Malay Confinement in Cross-cultural Perspective. Social Science and Medicine 15B:509_ 520.

Nichter, M. 1981 Idioms of Distress: Alternatives in the Expression of Psychosocial Distress: A Case Study from South India. Culture, Medicine, and Psychiatry 5:379-408.

Niner, S. L., R. Kokanovic, and D. Cuthbert 2013 Displaced Mothers: Birth and Resettlement-Gratitude and Complaint. Medical Anthropology: Cross Cultural Studies in Health and Illness 32:535-551. 
Oo, Z. M., and K. Kusakabe 2010 Motherhood and Social Network: Response Strategies of Internally Displaced Karen Women in Taungoo District. Women’s Studies International Forum 33:482-491.

Physicians for Human Rights 2012 Bitter Wounds and Lost Dreams: Human Rights under Assault in Karen State, Burma. www.physiciansforhumanrights.org/library/reports/bitter-wounds-andlostdreams. html (accessed December 15, 2010).

Queensland Health, State of Queensland 2011 BurmeseAustralians www.health.qld.gov.au/multicultural/health . . . /Burmese2011. pdf (accessed January 20, 2011).

Ram, K. 1998 Epilogue: Maternal Experience and Feminist Body Politics: Asian and Pacific Perspectives. In Maternities and Modernities: Colonial and Postcolonial Experiences in

Asia and the Pacific. K. Ram andM. Jolly, eds. Pp. 275-298. Cambridge: Cambridge University Press.

Rebhun, L. A. 1994 Swallowing Frogs: Anger and Illness in Northeast Brazil, Theme Issue: Conceptual Development in Medical Anthropology: A Tribute to M. Margaret Clark. Medical Anthropology Quarterly 8:360-382.

Sargent, C. 2012 "Deservingness” and the Politics of Health Care, Theme Issue Part I. Social Science and Medicine 74:855-857.

Singer, J. 2008 Listening to Refugee Bodies: The Naturopathic Encounter as a Cross-cultural Meeting Place. Ph.D. dissertation, Southern Cross University, Australia.

South, A. 2007 Karen Nationalist Communities: The "Problem" of Diversity. Contemporary Southeast Asia 29:55-76.

Tapias, M. 2006 Emotions and the Intergenerational Embodiment of Social Suffering in Rural Bolivia. Medical Anthropology Quarterly 20:399-415.

Thawnghmung, A. M. 2008 The Karen Revolution in Burma: Diverse Voices, Uncertain Ends. Washington, DC: East-West Center.

Tummala-Narra, P. 2004 Mothering in a Foreign Land. American Journal of Psychoanalysis 64:167-182.

U.S. State Department 2011 Human Rights Report on Burma http://www.state.gov/j/drl/rls/hrrpt/humanrightsreport/index.htm\#wrapper (accessed September 11, 2012).

Volk, L. 2009 "Kull wahad la haalu”: Feelings of Isolation and Distress among Yemeni Immigrant Women in San Francisco’s Tenderloin. Medical Anthropology Quarterly 23:297-416.

Supporting Information

Additional Supporting Information may be found in the online version of this article at the publisher’s website: Diagram 1: Heart Distress Schema/Network. 